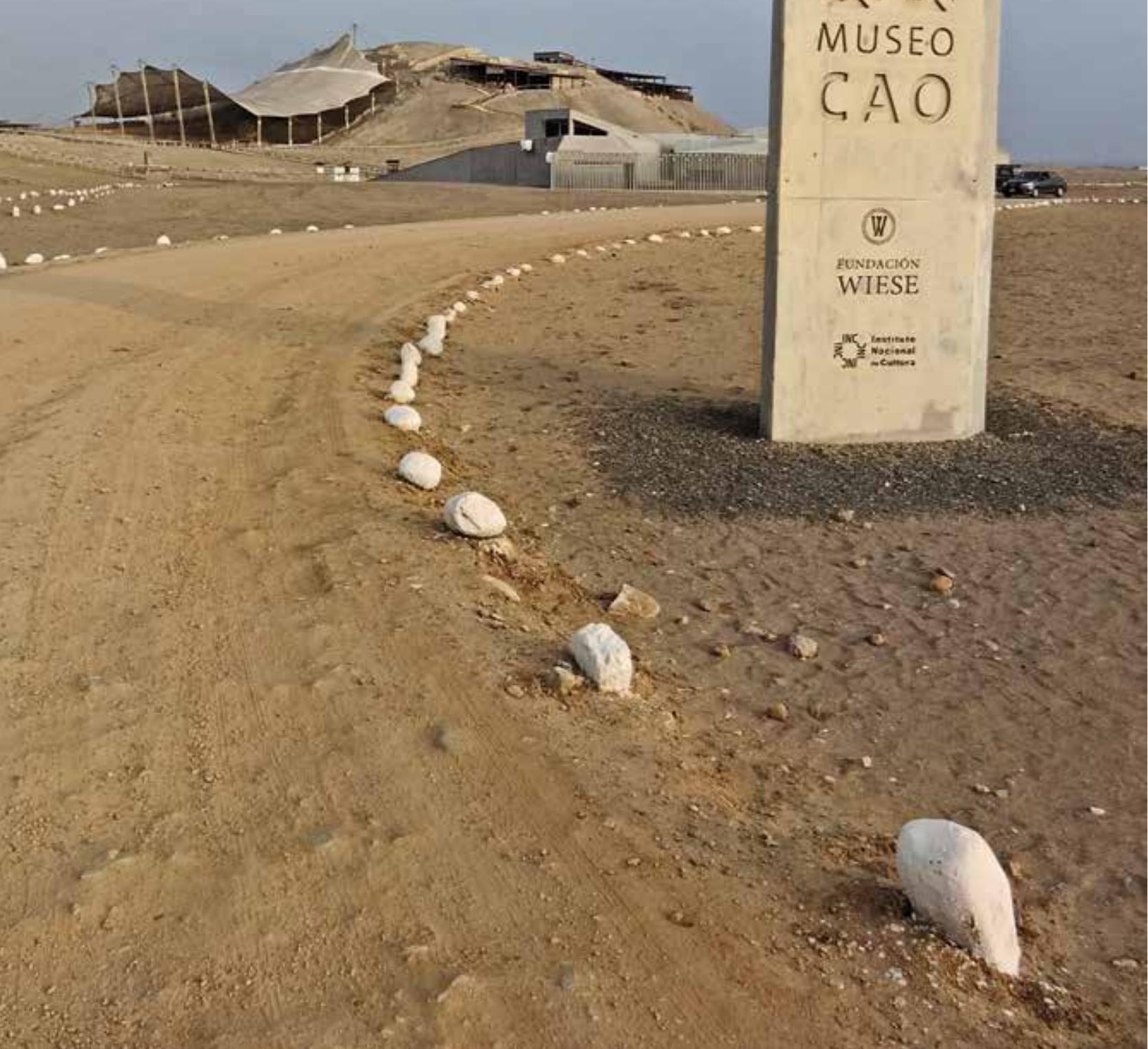




\section{Temas de Museología \\ Los primeros 25 años de un proyecto ejemplar}

Manuel Munive Maco

Instituto de Investigaciones Museológicas y Artísticas de la Universidad Ricardo Palma

Recuerdo perfectamente aquella reproducción de un sector de los altorrelieves de El Brujo, montada en el primer piso de la "Sala de Cultura" del Banco Wiese en la Av. Larco, a mediados de los años noventa. No hacía mucho que acababa de descubrirse esa fila de prisioneros desnudos, dirigiéndose hacia la izquierda del que mira, halados por el cuello mediante una larga soga. El que fuera hasta ese momento la evidencia mejor conservada de la plástica mural Moche motivó, sin duda, esa reproducción a tamaño real que permitió que "viéramos” en Miraflores una joya de la arqueología de La Libertad.

Pocos sospechaban que ese hallazgo sería el preludio de otros igualmente trascendentes: los monumentales murales de la Huaca de La Luna, en óptimo estado de conservación, por ejemplo, tomarían la posta de las grandes revelaciones arqueológicas durante un tiempo hasta que el año 2006, un equipo de especialistas, dirigido por el arqueólogo Régulo Franco, halló, en otra sección de la pirámide donde están "Los Prisioneros", un mausoleo que contenía un sarcófago de cien kilogramos. Este, a su vez, envolvía a una momia singular cuyo ajuar denotaba un poder y un prestigio excepcionales: se trataba de una mujer de 21 años, de poco menos de un metro y medio de estatura y con tatuajes predominantemente serpentiformes en las extremidades. Esa joven, hasta hoy la única gobernanta conocida en la historia de América, vivió hace 1700 años y murió por complicaciones al dar a luz. Así fue como ingresó a nuestro imaginario el nombre de la "Dama de Cao” y, en consecuencia, el del pueblo próximo: Magdalena de Cao.

Hace unos meses, la Fundación Wiese inició las conmemoraciones por sus primeros 25 años de trabajo científico ininterrumpido en El Brujo, organizando un Coloquio Internacional que se desarrolló los días 6 y 7 de agosto en el auditorio del Museo Cao. Participaron doce expositores ${ }^{1}$-arqueólogos,

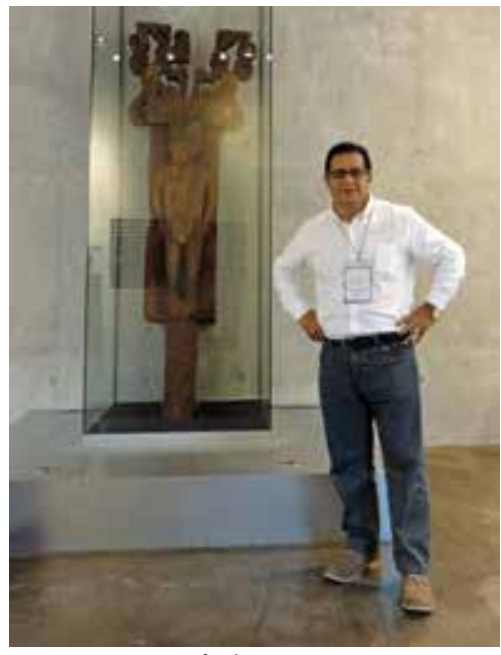

Régulo Franco

1 Régulo Franco, anfitrión y Director del Proyecto, Jefrey Quilter, Luis J. Castillo, Arabel Fernández, Sonia Guillén, Víctor Vásquez, Luis G. Lumbreras, Walter Alva, Angel Bustamante, John Rick, Carlos Wester, Ricardo Morales y Max Hernández. 


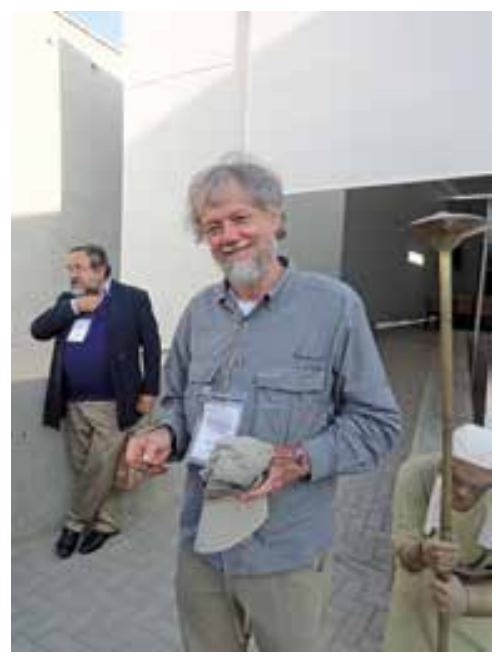

John Rick

antropólogos e historiadores, entre otros especialistas-, quienes aportaron información valiosa sobre los especímenes excavados allí mismo o sobre temas relacionados con los Moche y otras sociedades del Perú antiguo. Destacamos por la novedad de sus aportes y enfoques las ponencias de Jefrey Quilter ${ }^{2}$, Sonia Guillén ${ }^{3}$, John Rick ${ }^{4}$ y Carlos Wester ${ }^{5}$ y esperamos que, tal como lo anunciaron los organizadores, se publiquen todas en un volumen impreso.

Considerando que, en el Perú, los museos se hacen realidad con una lentitud semejante al desplazamiento de las placas tectónicas, resulta insólito -y modélico- que en 25 años -un plazo "corto" si tenemos en cuenta las proyecciones del trabajo arqueológico-, la Fundación Wiese haya alcanzado sus principales objetivos: proteger el sitio arqueológico del saqueo y la intemperie -la lluvia, la abrasión y la decoloración solar-, continuar con el trabajo de campo que seguirá aportando conocimiento y edificar un museo de sitio donde la preservación de la momia de la Señora de Cao, así como la custodia y la exhibición de los objetos provenientes de su tumba estén garantizadas. A esto se suma el que haya enriquecido ostensiblemente la llamada "Ruta Moche" y haber involucrado a la comunidad de Magdalena de Cao con los beneficios que el sitio arqueológico genera como destino turístico ${ }^{6}$.

Por donde lo miremos, el trabajo de la Fundación Wiese es ejemplar y parece imbuido del espíritu de su creador, el próspero empresario Guillermo "Pancho” Wiese. Su real vocación de arqueólogo, su curiosidad científica, su intuición de que en El Brujo subyacían evidencias valiosas y la pertinente y generosa administración de sus recursos económicos, fueron factores clave para que se produzca todo lo que ahora celebramos.

Nunca pude conocer a ese señor que en las fotografías documentales de la "Sala de Cultura" aparecía con un gran sombrero alón, en medio de la huaca promisoria y en relación entusiasta con los miembros de su equipo. Me hubiera gustado agradecerle personalmente que hayamos accedido a "otro nivel" en el conocimiento de la sociedad Moche gracias a su mecenazgo. Que el descubrimiento de la tumba de la Señora de Cao se haya producido poco tiempo después de que él falleciera, no es sino una de esas paradojas que debemos tomar como signo de lo extraordinario, tal como lo fue ese logro.

Las huellas descomunales del huaqueo demuestran que desde hace mucho tiempo se sabía que El Brujo escondía tesoros culturales. Régulo Franco comentó, durante una de las visitas guiadas del 7 de agosto, que gran parte de la mejor cerámica Moche esparcida por colecciones públicas y privadas del mundo entero provenían de allí. Tal vez esa misma fama fue la que atrajo al arqueólogo estadounidense Junius Bird, quien trabajó en la zona entre los años 1946 y 1947, excavando específicamente en Huaca Prieta, un montículo que forma parte del sitio arqueológico de El Brujo y del cual se obtuvo información crucial para

2 Leída por una funcionaria ya que él no pudo asistir.

3 "Momias femeninas: poder y tradición en el mundo prehispánico".

4 "Lo importante de Chavín para Moche: cambios y continuidades".

5 "Historia y género en el Templo de Chornancap, Lambayeque".

6 El taxista que me recogió del aeropuerto para llevarme directamente a Cao me contó en el camino que la puesta en valor de El Brujo y la afluencia turística habían definido su retorno a Ascope después de haber trabajado durante más de una década en Santiago de Chile. 
comprender la evolución de los diseños y las formas que perdurarán a lo largo de la vasta historia de la plástica andina.

Según la información vertida, el proyecto empezó a gestarse en Pachacamac, donde "Pancho" Wiese conoce a Régulo Franco y lo anima a que lo acompañe a Cao. El descubrimiento de la tumba del Señor de Sipán, había puesto sobre el tapete la urgencia de la excavación científica y parece ser que ese precedente estimuló aún más el interés del empresario por el rescate arqueológico. El trabajo en El Brujo em-

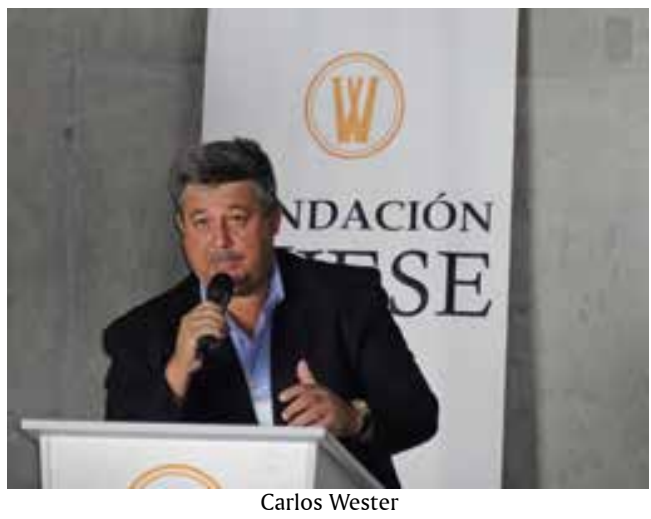
pieza realmente en 1990 y poco después es "premiado" con el hallazgo de secciones de algunos frisos policromos y en especial por el de "Los Prisioneros", el más extenso.

El 2006 se descubre el sarcófago de la Señora de Cao y El Brujo se abre al turismo. Desde entonces el trabajo en el lugar es febril en relación a su repercusión internacional: la revista National Geographic, publica un extenso artículo ese mismo año destacando, entre otras cosas, la singularidad de los tatuajes de la momia, ese detalle es particularmente enfatizado en la portada de la edición. Esto detona una mayor afluencia de visitantes y exige que la comunidad de Magdalena de Cao, poco a poco, empiece a acondicionar restaurantes y posadas. El Museo Cao se construye el 2008, abre sus puertas el 2009 y el 2012 se coproduce una película que llegó a ser vista por 102 millones de televidentes.

Ahora los pobladores sienten que ese patrimonio arqueológico les atañe y que deben contribuir con su preservación. La progresiva muralización de algunos establecimientos con la iconografía que caracteriza la pintura mural de El Brujo también es indicadora de esa toma de conciencia.

Ojalá hubieran en el Perú otros empresarios sensibles y cultos como "Pancho" Wiese, capaces de comprender que, tal como lo dijo el doctor Pedro Cabrera, un intelectual iqueño, "la cultura es la higiene del capital".

Reiteramos nuestro agradecimiento eterno a don "Pancho" y deseamos un feliz aniversario a la Fundación Wiese. 